\title{
Synergistic effects in cross-linked blends of ion-conducting PEO-/PPO-based unsaturated polyesters
}

\author{
Pia B. Sassmann ${ }^{1} \cdot$ Oliver Weichold ${ }^{1}$ (I) \\ Received: 12 March 2021 / Revised: 7 June 2021 / Accepted: 16 June 2021 / Published online: 8 July 2021 \\ (C) The Author(s) 2021
}

\begin{abstract}
Ion-conductive unsaturated polyesters (UP) were synthesised from poly(ethylene oxide) $\left(X_{n}=9,13,22,90\right)$ or poly(propylene oxide) $\left(X_{\mathrm{n}}=7,13,20,34,68\right)$ and maleic anhydride. Subsequently, the polyesters were doped with $\mathrm{LiClO}_{4}$ and cross-linked with styrene using a redox initiator. For PEO-based polyesters, the minimum resistivity is found at an $\mathrm{O} / \mathrm{Li}^{+}$molar ratio of $50 / 1$. In contrast, more lithium is required to reach the minimum when using PPO $\left(\mathrm{O} / \mathrm{Li}^{+}=10 / 1\right)$. Unlike the PEO-based polyesters, crosslinking of the PPO types gives rise to decreasing resistivities at increasing molecular weight. This correlates well with the transverse proton relaxation time determined by single-sided NMR, which is an indicator of the chain mobility. The crosslinking reaction of these UP with styrene exactly follows the predictions based on the copolymerisation parameters and is, therefore, not dependent on the ratio of styrene to UP double bonds as previously reported. Due to the opposing effects of the molecular weight on the ion conductivity of PEO- and PPO-based UP, 1:1 blends of short-chain PPO and long-chain PEO polyesters were cross-linked with styrene. The resulting networks showed a resistivity of $4 \mathrm{k} \Omega \mathrm{m}\left(\sigma=2.5 \cdot 10^{-4} \mathrm{~S} \cdot \mathrm{m}^{-1}\right)$, which is 5 times lower than the pure PEO and 3 times lower than the pure PPO materials.
\end{abstract}

Keywords Ion-conductive polyester $\cdot$ Unsaturated polyester $\cdot$ Impedance spectroscopy $\cdot$ Polymer blends $\cdot$ Polycondensation

\section{Introduction}

Polymer electrolytes are gaining increasing importance in the everyday life as seen by the massive use of diverse electrochemical devices such as lithium ion batteries for portable electronics and cars, [1] or electrochromic devices such as flat screens, smart windows [2] or monitoring systems. [3] These applications are based on the ability of electrolytes to serve as a medium for charge transfer. [4] The transport of ions through solid polymer electrolytes (SPE) depends on the enthalpy of solvation and the rate of dissociation of the ionic species as well as the mobility of the solvated ions within the polymer matrix. $[5,6]$ The solvation of low latticeenergy salts gives rise to the formation of polymer-salt complexes. [7-9] Therefore, the presence of heteroatoms (usually $\mathrm{O}, \mathrm{N}, \mathrm{S}$ ), which enable the solvation through interaction of their lone pairs with "free" cations, is a prerequisite for

Oliver Weichold

weichold@ibac.rwth-aachen.de

1 Institute for Building Materials Research, RWTH Aachen University, Aachen, Germany sufficient ionic conductivity. [10-14] The dissolved cations can subsequently move through the polymer electrolyte from one complexing site to another by a hopping process. $[9$, 14-17] High chain flexibility increases the segmental motion and improves the ion conductivity. Therefore, ion transport is faster in the amorphous polymer phase, [18-20] and the conductivity of SPE is significantly influenced by the glass transition temperature of the polymer. [4, 10, 11, 21] In addition, the hopping process is also affected by the location and distance between the coordination centres. [22]

The most widely studied polymer for SPE with conductivities of approximately $10^{-7}-10^{-4} \mathrm{~S} \cdot \mathrm{cm}^{-1}$ at ambient temperature is poly(ethylene oxide) (PEO). [20, 23, 24] $\mathrm{PEO}$ is a good complexing agent for lithium salts, albeit it has a rather low dielectric constant $(\varepsilon=5)$. [25] However, PEO tends to crystallise already at intermediate molecular weights $(>600$ $\mathrm{g} \cdot \mathrm{mol}^{-1}$ ) at room temperature, which significantly decreases the conductivity and therefore limits its usage. [25-27]

One approach to suppress crystallisation and to obtain amorphous, highly conductive polymers is to modify the molecular structure. Literature focusses on changing the $T_{\mathrm{g}}$, the dielectric constant, the ion solvation, salt dissociation, or ion hopping rates [28] by using polymer blends and copolymers, 
[5] combs [29] and ladders. [22, 30] Of these, the use of copolymers in combination with poly(propylene oxide) seems to be a promising approach to reduce crystallisation. [22] However, the conductivities of pure PPO are significantly lower than those of PEO, because of its lower dielectric constant and the hindered complexation of $\mathrm{Li}^{+}$ions by methyl groups. [5, 31, 32]

Angel et al. first investigated block copolymers containing $\mathrm{PEO}_{25}$ and $\mathrm{PPO}_{31}$ doped with lithium iodide. The incorporation of PPO inhibits the crystallisation of PEO and leads to highly conductive polymer electrolytes. [1,33] Furthermore, Khan et al. found that the conductivity more than doubles for blends of PEO $\left(M_{\mathrm{w}}=600,000\right)$ with PPO $\left(M_{\mathrm{w}}=1025\right)$ containing $\mathrm{LiClO}_{4}$, from $1.410^{-6}$ to $3.5510^{-6} \mathrm{~S} \cdot \mathrm{cm}^{-1}$ in comparison to pure PEO. [34] Also, for $\mathrm{PEO}_{20}-\mathrm{PPO}_{70}-\mathrm{PEO}_{20}$ triblock copolymers studied by Wang et al., the conductivity increases up to $8.910^{-6} \mathrm{~S} \cdot \mathrm{cm}^{-1}$ at a $\mathrm{O} / \mathrm{Li}^{+}$ratio of $8 / 1$ at $30{ }^{\circ} \mathrm{C}$. [35]

A further approach to suppress crystallisation is the use of cross-linked polyethylene glycols. Cross-linking [36] can be accomplished either directly via isocyanates, [22, 32, 37] hyperbranched polymers [38], or by using unsaturated polyesters as precursors. [39] The latter offers the advantage that polycondensation tolerates the presence of water and oxygen and cross-linked polyesters are resistant to alkaline hydrolysis. In addition, polyesters are not as toxic as polyurethanes and, therefore, are more suitable for the use in structural health monitoring of infrastructural buildings. [40]

The use of carbonyl-coordinating polymers in the form of carbonates such as poly(ethylene carbonate) [41] or poly(trimethylene carbonate) [42] or polyesters such as poly(caprolactones) [43-45] or poly(lactic acids) has additional advantages due to the interaction between the $\mathrm{Li}^{+}$ions and the carbonyl function. High dielectric constants of these polymers lead to effective charge separation of the salts, which further results in high concentration of charge carriers $[20,30]$. Although, the weaker coordination of $\mathrm{Li}^{+}$compared to polyethers leads to the formation of more ion pairs, which lowers the overall conductivity, the lithium ions are less immobilised. This causes faster ion transport (high $\mathrm{Li}^{+}$transport number) $[41,46]$. The balance of ion coordination, segmental mobility, and ion pairing plays a key role in current research $[13,46]$ and can be tuned for example by the use of copolymers, [36, 42, 43, 47, 48] blends [49], or inorganic fillers [50-54]. Johansson et al. synthesised polyester/ polycarbonate SPEs for high-temperature applications via UV radiation with good ionic conductivity $\sim 10^{-4} \mathrm{~S} \cdot \mathrm{cm}^{-1}$ and long cycle periods [55].

There are some reports in literature on cross-linked networks based on unsaturated polyesters of PEO/PPO as well as blends of commercial UP with PEO and/or PPO, but mainly with the focus on the morphology, miscibility, and thermal properties. [56-60] In our previous paper, we studied the curing kinetics and impedance behavior of PEO-based unsaturated polyesters. [40] Since cross-linking can potentially suppress the crystallisation of PEO, the question, thus, arises how increasing the molecular weight of the polyether block and to what extent substituting PEO for PPO affects the performance of these systems. Herein, we present the combination of the conductive properties of PEO-based UP with the structural properties of PPO-based UP, which appear to exhibit a synergistic effect in terms of the ionic conductivity.

\section{Experimental}

\section{Materials}

Poly(ethylene glycol) $\left(M_{\mathrm{w}}=400 \mathrm{~g} \cdot \mathrm{mol}^{-1}\right.$, Carl Roth GmbH \& Co.KG; $M_{\mathrm{w}}=600 \mathrm{~g} \cdot \mathrm{mol}^{-1}$, Merck; $M_{\mathrm{w}}=1000 \mathrm{~g} \cdot \mathrm{mol}^{-1}$, Calbiochem; $M_{\mathrm{w}}=2000 \mathrm{~g} \cdot \mathrm{mol}^{-1}$ and $M_{\mathrm{w}}=4000 \mathrm{~g} \cdot \mathrm{mol}^{-1}$, Sigma-Aldrich Chemistry), poly(propylene glycol) $\left(M_{\mathrm{w}}=\right.$ $425 \mathrm{~g} \cdot \mathrm{mol}^{-1}, M_{\mathrm{w}}=725 \mathrm{~g} \cdot \mathrm{mol}^{-1}$ and $M_{\mathrm{w}}=1200 \mathrm{~g} \cdot \mathrm{mol}^{-1}$, Sigma-Aldrich; $M_{\mathrm{w}}=2000 \mathrm{~g} \cdot \mathrm{mol}^{-1}$, Aldrich Chemistry; $M_{\mathrm{w}}$ $=4000 \mathrm{~g} \cdot \mathrm{mol}^{-1}$, Alfa Aesar), maleic anhydride (Alfa Aesar), $p$-toluensulfonic acid monohydrate (Carl Roth GmgH \& Co. KG), methyl ethyl ketone peroxide (Promox P211 TX, 35\% in aliphatic solvents, Mühlmeier GmbH \& Co. KG), cobalt(II) 2ethylhexanoate ( $65 \%$ in mineral spirits, Sigma-Aldrich), styrene (MERK), and anhydrous $\mathrm{LiClO}_{4}$ (Alfa Aesar) were used as-received.

\section{Synthesis of unsaturated polyesters}

The unsaturated polyesters were prepared from poly(ethylene glycol) (PEO) or poly(propylene glycol) (PPO) with maleic anhydride in the presence of $p$-toluenesulfonic acid monohydrate as catalyst. The reactants were used equimolarly only for determining the reaction kinetics. In other cases the molar ratio of reactants was adjusted to a theoretical degree of polymerisation of 6 . Details of the sample compositions are given in Table S1 in the Supplementary information. For all experiments, the reactants were dissolved in toluene $(c=0.07$ $\mathrm{mol} / \mathrm{l})$ in a round bottom flask, and the polycondensation was performed at $140^{\circ} \mathrm{C}$ under nitrogen atmosphere for $24 \mathrm{~h}$ using a Dean-Stark apparatus. The conversion was determined by titration with $0.1 \mathrm{M} \mathrm{KOH}$ using phenolphthalein as an indicator. For that, the solvent was evaporated, and $0.2 \mathrm{~g}$ polyester was dissolved in acetone and 3 drops of $0.1 \mathrm{M}$ phenolphthalein solution were added. The reaction kinetics was determined in the same way by titration of $1 \mathrm{ml}$ polyester solution.

\section{Curing of UP with styrene}

The unsaturated polyesters (e.g. $2.00 \mathrm{~g}$ for $50 \mathrm{E}_{9}$ ) were mixed with $1 \mathrm{M} \mathrm{LiClO}_{4}$ solution in acetonitrile to obtain the desired $\mathrm{O}$ to $\mathrm{Li}^{+}$ratios (e.g. $0.720 \mathrm{ml}, 0.730 \mathrm{mmol}$, for $50 \mathrm{E}_{9}$ with a 
ratio of 50/1). After obtaining a homogeneous solution, acetonitrile was removed by lyophilisation.

The mixture containing unsaturated polyester and $\mathrm{LiClO}_{4}$ were mixed with the desired amount of styrene (e.g. $600 \mathrm{mg}$, $5.70 \mathrm{mmol}$, for $30 \mathrm{wt} \%$ using $50 \mathrm{E}_{9}$ ) at $60{ }^{\circ} \mathrm{C}$. After that, methyl ethyl ketone peroxide (MEKP) (e.g. $78.0 \mathrm{mg}$, $120 \mu \mathrm{mol}$ for $3 \mathrm{wt} \%$ ) and cobalt(II) 2-ethylhexanoate solution (e.g. $39.0 \mathrm{mg}, 700 \mu \mathrm{mol}$ for $1.5 \mathrm{wt} \%$ ) were added and cured at $60{ }^{\circ} \mathrm{C}$ overnight. All sample compositions are given in Table S2.

\section{Electrochemical impedance spectroscopy (EIS)}

Potentiostatic EIS measurements were performed using a PCI4/300 Gamry Potentiostat (C3 Prozess und Analysetechnik $\mathrm{GmbH})$. Standard electroporation cuvettes ( $a$ $=4 \mathrm{~mm})$ with two aluminium oxide electrodes $(19 \times 8 \mathrm{~mm})$ were filled with the liquid $\mathrm{Li}$-doped polyester resin, and the mixture was fully cured at $60{ }^{\circ} \mathrm{C}$. The cured polyester was analysed by impedance measurements recorded in a frequency $(f)$ range of $0.01 \mathrm{~Hz}-10 \mathrm{MHz}$ with an ac voltage of $141 \mathrm{mV}$ at room temperature. The electrolyte resistance is calculated by fitting an equivalent circuit model for systems containing blocking electrodes (Fig. 1).

\section{Differential scanning calorimetry}

DSC measurements were performed on a 206 Phoenix (Netzsch) in aluminium crucibles operating in a temperature range from -80 to $150{ }^{\circ} \mathrm{C}$ under nitrogen atmosphere. The dynamic measurements were carried out using an empty aluminium crucible as reference. All samples were first heated from room temperature to $150^{\circ} \mathrm{C}$ and cooled down to $-80{ }^{\circ} \mathrm{C}$. In a second run, the sample was reheated in steps of $10 \mathrm{~K} / \mathrm{min}$ to $150{ }^{\circ} \mathrm{C}$ and cooled down to $-22^{\circ} \mathrm{C}$. The procedure was then repeated with a heating rate of $3 \mathrm{~K} / \mathrm{min}$.

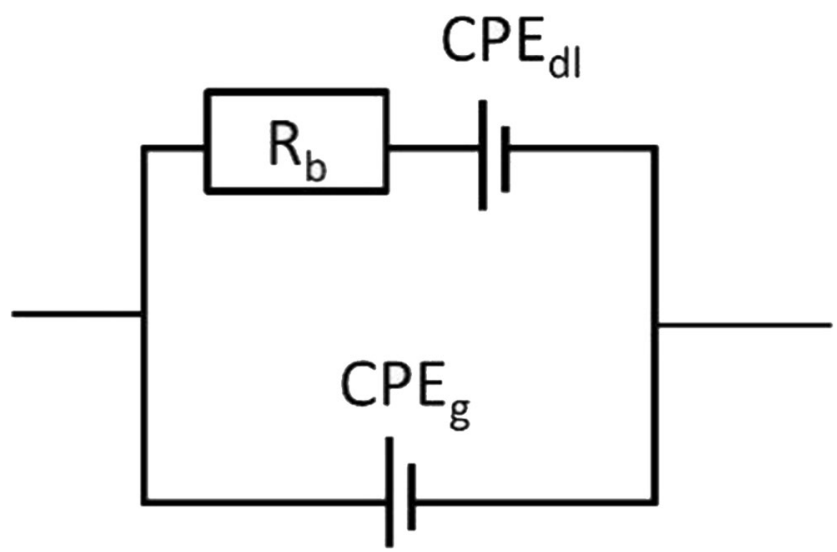

Fig. 1 Equivalent circuit for fitting the EIS response using blocking electrodes containing two constant phase elements (CPE) and an ohmic resistor (R) [25]

\section{Single-sided NMR}

Single-sided NMR measurements were performed on a PM5 NMR-Mouse ${ }^{\circledR}$ (Magritek) by tracing the spin-spin relaxation decay $\left(T_{2}\right)$ using a Carr-Purcell-Meiboom-Gill (CPMG) sequence. The cured samples were placed on a glass slide (1.3 mm thickness) on top of the sensor, and the measurements were carried out at a sensitive volume of $200 \mu \mathrm{m}$. The number of scans was set to 512 with a repetition delay of $1.5 \mathrm{~s}$, and the number of echoes was adjusted to 3000 to provide a good signal-to-noise ratio. The acquisition time per echo was set to $5 \mathrm{~ms}$, and the NMR experiments were performed at $21^{\circ} \mathrm{C}$.

\section{Results and discussion}

The unsaturated polyesters are prepared by acid-catalysed polycondensation of polyetherdiols with maleic anhydride (MSA) (Fig. 2). The theoretical degree of polymerisation was adjusted to 6 by using a calculated excess of the diol. All types of polyesters were doped with lithium perchlorate to achieve ion conductivity and then cross-linked (cured) by radical copolymerisation with styrene using methyl ethyl ketone peroxide (MEKP) and cobalt(II) 2-ethylhexanoate (Co-Oct) as redox initiator to increase the mechanical stability [40].

The sample identifiers are explained in Table 1. For unsaturated polyesters that are not cross-linked with styrene, the identifier simply refers to the amount of the repeat units; e.g. $\mathrm{E}_{9}$ refers to a polyester made from $\mathrm{PEO}$ with $9 \mathrm{EO}$ repeat units and MSA. For the cross-linked samples containing $\mathrm{LiClO}_{4}$, the identifier is, e.g. $50 \mathrm{E}_{9}$, where the first number specifies the numerical ratio of the repeat units to $\mathrm{Li}^{+}$, in this case 50:1. An additional italic letter characterises a blend, e.g. $17 B \mathrm{E}_{45} \mathrm{P}_{7}$ being a blend of $\mathrm{E}_{45}$ and $\mathrm{P}_{7}$ with an $\mathrm{O} / \mathrm{Li}^{+}$ratio of 17. A detailed sample composition is given in Table $\mathrm{S} 1$ for the polycondensation reaction and Table S2 for the curing parameters.

The polycondensation of the pure PEO or PPO with maleic anhydride to give $\mathrm{E}_{\mathrm{x}}$ and $\mathrm{P}_{\mathrm{y}}$ (Fig. 1A, B) was monitored over time using the acid number (Supplementary Figs. S1, S2), and the results were fitted using a second-order kinetics (Supplementary Figs. S3, S4). The first phase in the reaction is the nucleophilic opening of the cyclic anhydride by the diol component and occurs so fast compared to the subsequent acid-catalysed esterification (second phase) that it is usually not directly observed. The second phase nicely obeys the second-order kinetics up to a conversion of $89 \%$ for $\mathrm{E}_{9}$ and $84 \%$ for $\mathrm{P}_{7}$ at $4500 \mathrm{~min}$. Table $\mathrm{S} 3$ lists the second-order rate constants. As previously reported, the reaction rate decreases for both PEO and PPO with increasing molecular weight (Fig. 3 ) due to the increased viscosity of the reaction mixture and the lower mobility of the higher molecular weight reactants [61]. Generally, the rate constants for PPO are approximately 
<smiles>O=C1C=CC(=O)O1</smiles><smiles>CC(C)OCCC(C)(C)O</smiles>

$\mathrm{m}$<smiles>CC(O)CO</smiles>

toluene

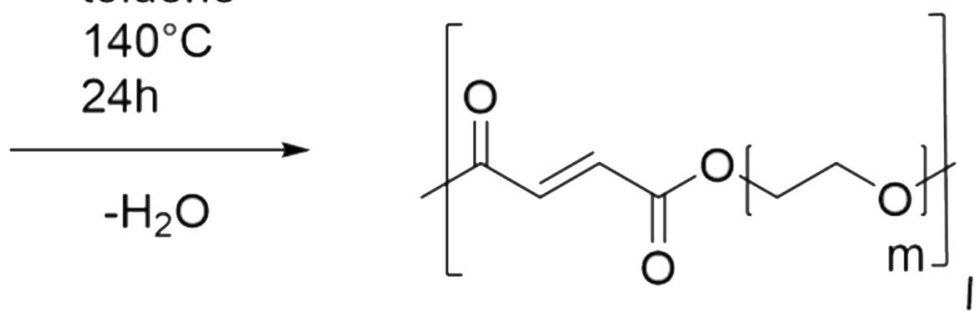

toluene

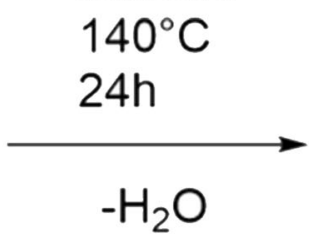<smiles>CC(C)OC(=O)/C=C/C(=O)C(C)(C)C</smiles>

Fig. 2 Polycondensation reaction of maleic anhydride (MSA) and PEO, PPO

2-3 times lower than those for PEO at comparable molecular weights. One reason could be that the PPO chain bears at one end a secondary hydroxyl group, which is sterically more hindered than the primary ones of PEO.

The unsaturated polyesters are then doped with $\mathrm{LiClO}_{4}$ to cause ion conductivity and, with regard to future applications as sensor materials, cross-linked with styrene in order to increase the mechanical stability [40]. The styrene polymerisation was found to go to completeness, as IR spectroscopy did not show any signs of residual monomer evidenced by the absence of the characteristic styrene bands at $\widetilde{v}=778,912$, and $1296 \mathrm{~cm}^{-1}$. Differential scanning calorimetry (DSC) measurements confirm this finding as no post-curing was found at higher temperatures (Supplementary Fig. 5).

The lithium concentration has an enormous influence on the electrical properties of polymer electrolytes and is usually reported as molar ratio of ether repeat units to $\mathrm{Li}^{+}$ions (e.g. $\left.\mathrm{O} / \mathrm{Li}^{+}\right)$. In analogy to low-molecular salt solutions, the resistivity of polymer electrolytes decreases with increasing $\mathrm{Li}^{+}$ content (increase of $\mathrm{O} / \mathrm{Li}^{+}$) and passes a minimum beyond which the resistivity increases again. The occurrence of a minimum was assigned to a higher ion aggregation and an increased viscosity at higher salt concentrations. [5] This, in turn, reduces both the number of free ions and the ionic mobility simultaneously. The location of the maximum depends

Table 1 Sample composition of cured unsaturated polyesters with related $\mathrm{O} / \mathrm{Li}^{+}$ratio

\begin{tabular}{ll}
\hline Abbreviation & Explanation \\
\hline$B$ & Blend \\
First number & $\mathrm{O} / \mathrm{Li}^{+}$ratio \\
Subscript number (s) & Repeat units in ether blocks \\
\hline
\end{tabular}

on the dielectric constant of the polymer and the temperature. A higher dielectric constant shifts the occurrence of ion pairing to higher salt concentrations, similar to higher temperatures which reduce the solution viscosity. [4] For lithium perchlorate-doped pure PEO, the minimum was found to be $\mathrm{O} / \mathrm{Li}^{+}=50[23]$ and this was also found for the PEO-based UP which is consistent with previously reported literature [39, 40, 62].

Similar to PEO, the resistivity of cross-linked PPO systems decreases with increasing $\mathrm{Li}^{+}$content and passes a minimum, which was reported to be $25: 1$ for isocyanate cross-linked systems when using $\mathrm{LiClO}_{4}$ as dopant. [31-33, 63] In contrast to PEO, PPO is a weaker solvent for lithium salts due to a smaller dielectric constant caused by the methyl group protruding from the ether PPO backbone. The presence of a methyl group results in a larger diameter of helical secondary

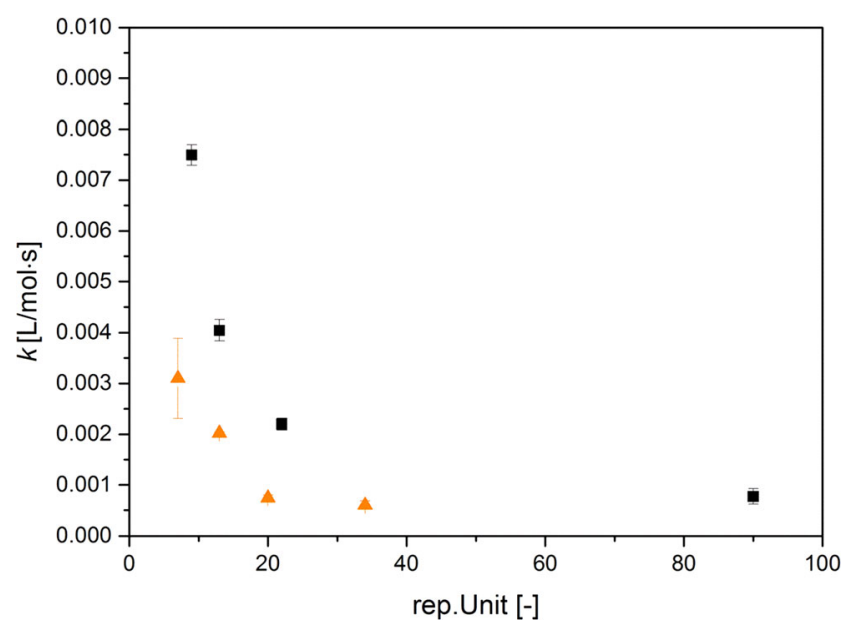

Fig. 3 Rate constants for the polycondensation of maleic anhydride with PEO ((squares) $E_{9-91}$ ) and PPO ((triangles) $\mathrm{P}_{7-34}$ ) as function of the molecular weight 
structure wrapping around the lithium ions. $[25,64]$ As a result, more ions are needed to overcrowd the helix in comparison to PEO and hamper the movement [5]. For styrenecured PPO polyesters, the minimum was found at a molar ratio $\mathrm{O} / \mathrm{Li}^{+}=10$ (Fig. 4).

Compared to similar isocyanate cross-linked PPO networks $\left(\sigma=10^{-7} \mathrm{~S} \cdot \mathrm{cm}^{-1}\right)$, the conductivity of cross-linked PPO polyesters is ten times higher at $\sigma=10^{-6} \mathrm{~S} \cdot \mathrm{cm}^{-1}$ and, thus, in the conductivity range reported for pure $\mathrm{PPO}\left(10^{-5}\right.$ to $\left.10^{-6} \mathrm{~S} \cdot \mathrm{cm}^{-1}\right)[31,32]$.

With regard to the molecular weight, the resistivity of PEObased ion-conducting polyesters at $\mathrm{O} / \mathrm{Li}^{+}=50\left(50 \mathrm{E}_{\mathrm{x}}\right)$ was found to increase with molecular weight (Fig. 5, squares). The increase in resistance is moderate for a small number of repeat units $50 \mathrm{E}_{9-22}$. The exception is $50 \mathrm{E}_{13}$ which represents the minimum. The significant increase in resistivity of the cross-linked UP $50 \mathrm{E}_{45}$ is, thus, assigned to crystallisation of the higher molecular weight polyesters, which hampers the movement of ions. In line with this, the cross-linked $50 \mathrm{E}_{9}$, $50 \mathrm{E}_{13}$, and $50 \mathrm{E}_{22}$ have macroscopically the appearance of rubber erasers, while $50 \mathrm{E}_{45}$ and $50 \mathrm{E}_{91}$ feel like compact powders. This observation is consistent with previously studied non-cross-linked, lithium-doped PEO polymer electrolytes, for which the resistivity decreases with increasing number of repeat units up to 18. [19] Beyond that, the resistivity increases because of higher crystallinity and finally levels off at 91 repeat units. $[11,19]$

In contrast, the resistivity of lithium-doped PPO-based UP $\left(10 \mathrm{P}_{7-69}\right)$ was found to decrease with increasing molecular weight from $15.43 \mathrm{k} \Omega \mathrm{m}$ for $10 \mathrm{P}_{7}$ down to $194.3 \Omega \mathrm{m}$ for $10 \mathrm{P}_{69}$ (Fig. 5, triangles). On the molecular level, the movement of the ions along the chain (intrachain hopping) is faster than the transition from one chain to another (interchain hopping). [1, 15, 65] Increasing the molecular weight of the ether block should, therefore, allow the ions to span greater

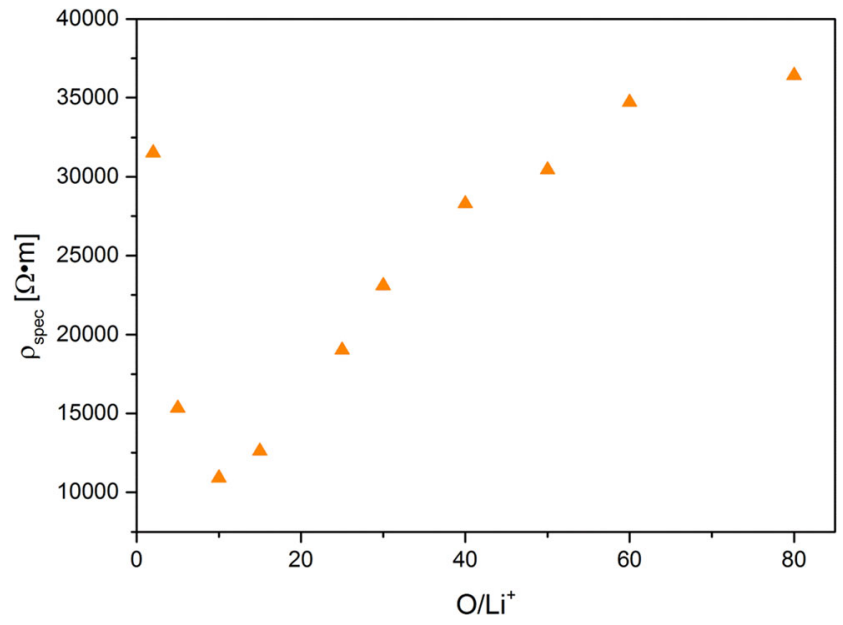

Fig. 4 The resistivity of styrene-cured PPO-based UP passes a minimum at $\mathrm{O} / \mathrm{Li}^{+}=10$, exemplary shown for $\mathrm{XP}_{13}$ measured at room temperature $(\mathrm{X}=2,5,10,15,30,40,50,60,80)$

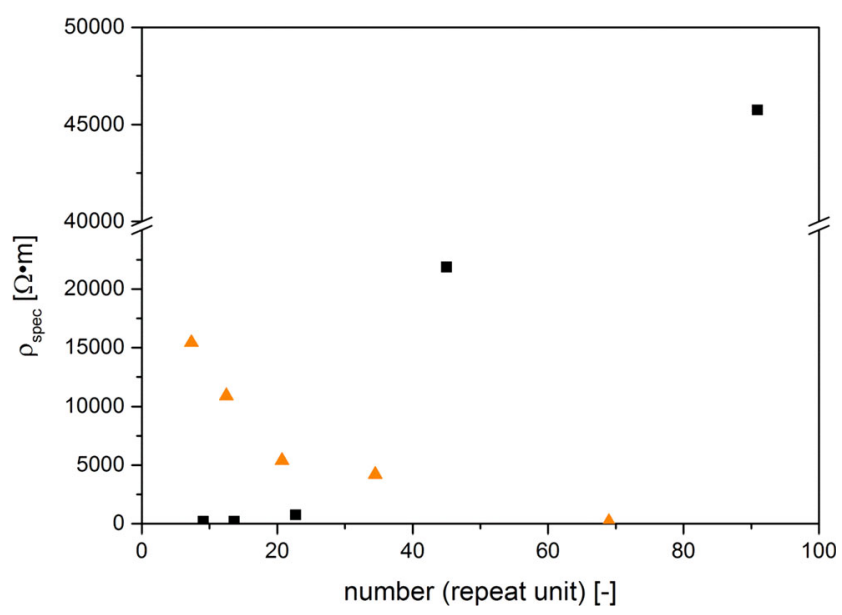

Fig. 5 The resistivity of lithium-doped, styrene-cured unsaturated polyesters $50 \mathrm{E}_{\mathrm{x}}\left(\mathrm{O} / \mathrm{Li}^{+}=50\right.$ (squares) $\left.\mathrm{X}=9,13,22,45,90\right)$ and $10 \mathrm{P}_{\mathrm{y}}\left(\mathrm{O} / \mathrm{Li}^{+}=\right.$ 10 (triangles) $\mathrm{Y}=7,13,20,34,68$ ) as a function of the number of repeat units in the ether block. Note: the decrease in slope beyond $50 \mathrm{E}_{45}$ is due to the interruption of the $y$-axis at $40 \mathrm{k} \Omega \mathrm{m}$. In a continuous scale, the trend is linear

distances along the same chain rather than having to undergo time-consuming interchain hopping. However, this effect is normally counteracted by the increased viscosity at high molecular weights, which hinders ion movement. Although all unsaturated polyesters $\left(\mathrm{P}_{7-69}\right)$ are liquid, their viscosity increases with increasing molecular weight (Supplementary Fig. 6) and, thus, the opposite behaviour was expected. To get more insight into the $10 \mathrm{P}_{\mathrm{y}}$ system, single-sided nuclear magnetic resonance was used to measure the amplitudeweighted average of the transverse proton relaxation time $\left\langle T_{2}\right\rangle$, which correlates with the chain mobility. In brief, the transverse relaxation of exited protons can be approximated by a sum of exponential functions (Eq. 1) and from this, $\left\langle T_{2}\right\rangle$ is calculated by integrating the normalised echo sum over time (Eq. 2). [66-68]

$s(t)=\sum_{i} A_{i} e^{\frac{t}{T_{2, i}}}$

$\int_{0}^{\infty} \frac{s(t)}{s(0)} d t=\sum_{i} \omega_{i} T_{2, i}=\left\langle T_{2}\right\rangle$

with $\omega_{i}={ }_{A_{i}} A_{0}=$ relative amplitudes of the components.

In general, lower $\left\langle T_{2}\right\rangle$ values indicate lower average chain mobility and vice versa. However, the effective transversal relaxation time is not an absolute measure for the chain mobility and comparisons can only be made within a group of samples. For example, the soft rubber-like PEO-based polyesters $50 \mathrm{E}_{22}$ exhibit $\left\langle T_{2}\right\rangle$ times of approximately $2.5 \mathrm{~ms}$, similar to the hard, rubber-like PPO-based polyester $10 \mathrm{P}_{34}$ at approximately $3 \mathrm{~ms}$ (Fig. $6 \mathrm{~A}$ and $\mathrm{B}$ ).

For PEO-based polyesters, $\left\langle T_{2}\right\rangle$ decreases with increasing molecular weight, indicating a decrease in the chain mobility (Fig. 6A, squares). At the same time, the resistivity increases (Fig. 6A, bars), which is in accordance with the general 


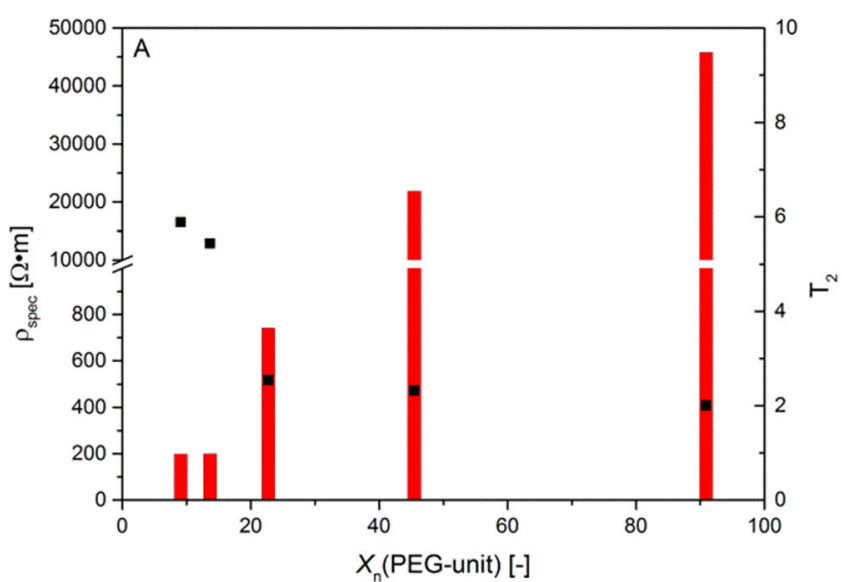

Fig. 6 Resistivity (solid bars) determined by electrochemical impedance spectroscopy and amplitude-weighted average of the proton relaxation time $\left\langle T_{2}\right\rangle$ (squares) determined by single-sided nuclear magnetic

theory. [5] In contrast, for the styrene-cured PPO-based polyesters $10 \mathrm{P}_{\mathrm{y}},\left\langle T_{2}\right\rangle$ increases with increasing molecular weight indicating higher chain mobility despite the increased viscosity of the uncured polyesters (Fig. 6B, squares). This effect is additionally supported by a change in the glass transition temperature. DSC measurements showed the glass transition temperature to decrease linearly with increasing molecular weight of the PPO block (Supplementary Fig. 7) indicating the onset of cooperative segmental motion to shift to lower temperatures.

However, there seems to be no simple correlation between $\left\langle T_{2}\right\rangle$ and the resistivity, as other material properties, such as the texture, may affect $\left\langle T_{2}\right\rangle$. This can be seen by comparing $10 \mathrm{P}_{34}$ and $10 \mathrm{P}_{69}$ (Fig. 6B): the increase in $\left\langle T_{2}\right\rangle$ is much less pronounced than the decrease in resistivity. The reason could be that $10 \mathrm{P}_{7,13,20,34}$ are rubber-like, while $10 \mathrm{P}_{69}$ has the consistency of a waxy paste.

The question arises if the increase in chain mobility and with it the decrease in resistance of the $10 \mathrm{P}_{\mathrm{y}}$ samples is caused by incomplete cross-linking. It was previously reported that UP chains are typically connected by three styrene units, while $3-7 \%$ of the UP double bonds remain unreacted. Additional homopolymerisation of styrene was only found to occur, if the molar ratio of styrene to UP double bonds exceeds 9. [69, 70] A prevalence of styrene homopolymerisation would lead to both longer poly(styrene) segments between the UP chains and a blend of poly(styrene) and the UP. In the present $10 \mathrm{P}_{\mathrm{y}}$ series, the mass ratio of styrene to the unsaturated polyester is kept constant. Thus, the molar ratio of styrene to UP double bonds (i.e. the MSA units) increases linearly (Supplementary Fig. S8) from 1.74 for the $10 \mathrm{P}_{7}$ sample to 14.1 for $10 \mathrm{P}_{69}$ (Table 2).

Successful cross-linking can be monitored by the C-H out of plane normal vibrations of the phenyl groups directly attached to the polyester chain at $763 \mathrm{~cm}^{-1}$, which marks the cross-linking point at the transition from UP to poly(styrene).

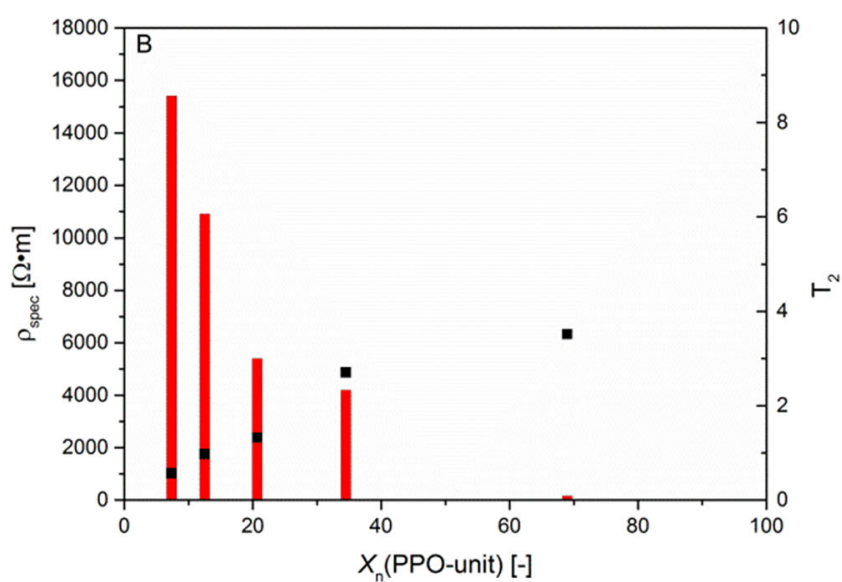

resonance of styrene-cured $50 \mathrm{E}_{\mathrm{x}}(\mathrm{X}=9,13,22,45,90)(\mathbf{A})$ and $10 \mathrm{P}_{\mathrm{y}}$ $(\mathrm{Y}=7,13,20,34,68)(\mathbf{B})$ as a function of the molecular weight

[71-74] The curing reaction can additionally be followed by the $\mathrm{C}=\mathrm{C}$ stretching vibration of the unsaturated polyester at $1646 \mathrm{~cm}^{-1}$. In addition, the vibration at $700 \mathrm{~cm}^{-1}$ representing the poly(styrene) chain in both the homopolymer and longer segments between the UP chains needs to be considered.

When comparing $10 \mathrm{P}_{7}$ (styrene/MSA $=1.74$ ) with $10 \mathrm{P}_{13}$, 20,34 , it is noticeable that very low styrene/MSA ratios give rise to very few cross-linking points (Fig. 7, squares) and leave a larger number of unreacted double bonds in the polyester backbone (Fig. 7, circles). At the same time, the poly(styrene) vibration is less pronounced. Since literature postulates an average of 3 styrene units forming the cross-link, every other UP double bond should statistically remain in $10 \mathrm{P}_{7}$. With increasing styrene/MSA ratio, the number of unreacted double bonds decreases, while the number of cross-linking points and the poly(styrene) vibration increase. This is in accordance with the mechanism of radical copolymerisation. However, $10 \mathrm{P}_{69}$ exhibits an excessive signal of poly (styrene), whereas the other two vibrations change only slightly compared to $10 \mathrm{P}_{34}$. Taking into consideration that maleic anhydride as a monomer is incorporated into the UP as fumaric diester, the copolymerisation during the curing reaction can be

Table 2 Molar ratios of styrene to maleic anhydride (MSA) in cured samples using $\mathrm{O} / \mathrm{Li}^{+}=10$

\begin{tabular}{llll}
\hline Sample & MSA $^{1} / \mathrm{mol}$ & Styrene $^{2} / \mathrm{mol}$ & Styrene/MSA \\
\hline $10 \mathrm{P}_{7}$ & $3.31 \cdot 10^{-3}$ & $5.76 \cdot 10^{-3}$ & 1.74 \\
$10 \mathrm{P}_{13}$ & $2.08 \cdot 10^{-3}$ & $5.76 \cdot 10^{-3}$ & 2.78 \\
$10 \mathrm{P}_{21}$ & $1.30 \cdot 10^{-3}$ & $5.76 \cdot 10^{-3}$ & 4.42 \\
$10 \mathrm{P}_{34}$ & $0.80 \cdot 10^{-3}$ & $5.76 \cdot 10^{-3}$ & 7.18 \\
$10 \mathrm{P}_{69}$ & $0.41 \cdot 10^{-3}$ & $5.76 \cdot 10^{-3}$ & 14.1
\end{tabular}

${ }^{1}$ Amount of maleic anhydride within $2 \mathrm{~g}$ of unsaturated polyester

${ }^{2}$ Equivalent to $30 \mathrm{wt} \%$ for the curing reaction with $2 \mathrm{~g}$ of unsaturated polyester 


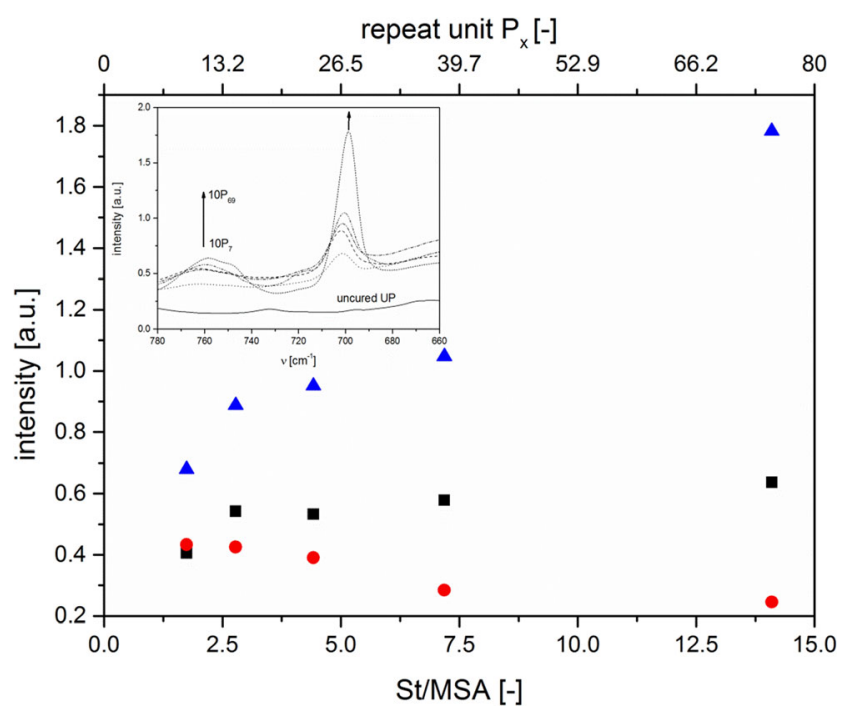

Fig. 7 Development of three characteristic IR bands used to evaluate the cross-linking reaction for the $10 \mathrm{P}_{\mathrm{y}}$ series $(\mathrm{Y}=7,13,20,34,68)$ : poly(styrene) at $\tilde{\mathrm{v}}=700 \mathrm{~cm}^{-1}$ (triangles), double bond of the unsaturated polyester at $\tilde{V}=1646 \mathrm{~cm}^{-1}$ (circles) and cross-linking point at the transition from UP to PS at $\tilde{\mathrm{v}}=763 \mathrm{~cm}^{-1}$ (squares)

represented by styrene (monomer 1) and diethyl fumarate (monomer 2). For this system, the copolymerisation parameters are $r_{1}=0.318$ and $r_{2}=0.013$. [75] According to the definition of the copolymerisation parameters, values $<1 \mathrm{im}-$ ply the preference for heteropolymerisation. However, for styrene, the value of $r_{1}=0.318$ indicates that styrene homopolymerisation is also possible. In contrast, the value for diethyl fumarate virtually rules out any fumarate homopolymerisation. Since the product $\mathrm{r}_{1} \cdot \mathrm{r}_{2} \approx 0$, the copolymerisation proceeds in a mostly alternating fashion. The amount of styrene incorporated during the cross-linking reaction with the UP can be determined by IR spectroscopy using the bands described above. Comparing these experimental values with the theoretical amounts predicted by the corresponding copolymerisation diagram provides an exact match (Fig. 8). This leads to the assumption that homopolymerisation to "free" polystyrene does not occur even for $10 \mathrm{P}_{69}$ and even though the calculated styrene to MSA ratio is greater than 14 . Softening of the $10 \mathrm{P}_{\mathrm{x}}$ polyester with increasing molecular weight is therefore not due to incomplete cross-linking. High $\left\langle T_{2}\right\rangle$ values, on the other hand, in combination with decreasing $T_{\mathrm{g}}$, suggest that more flexible networks with larger mesh sizes are formed.

It has previously been shown that the resistance for $50 \mathrm{E}_{\mathrm{x}}$ increases with increasing chain length $x$ due to greater crystallinity (cf. Fig. 5 squares) and the opposite behaviour is found for $10 \mathrm{P}_{\mathrm{y}}$ (cf. Fig. 5 triangles). The question thus arises if blending liquid $\mathrm{P}_{7}$ the with $\mathrm{E}_{45}$ and subsequent cross-linking can form networks with lager mesh size and suppress the crystallisation of the PEO, which should both cause a decrease in the resistivity of such blends.

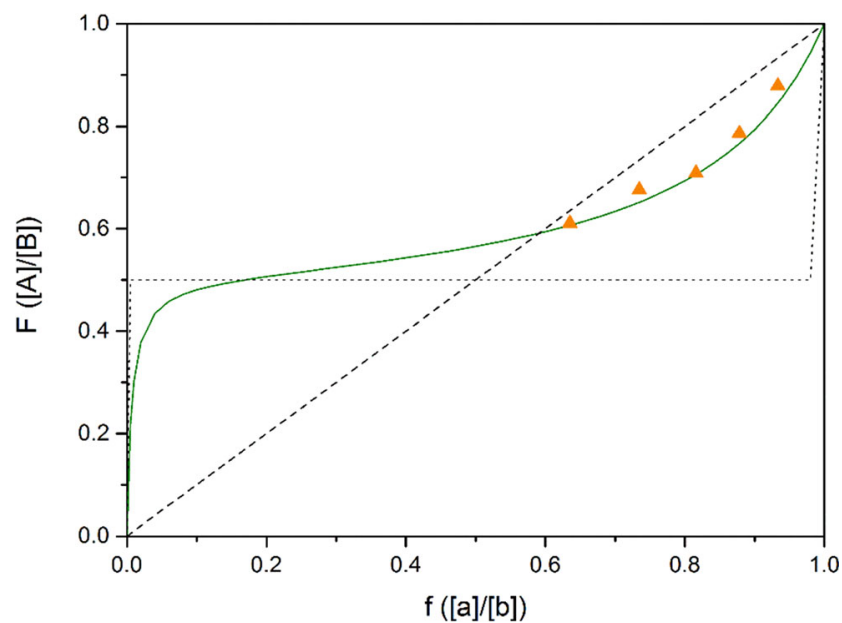

Fig. 8 Calculated copolymerisation diagram of styrene and diethyl fumarate (green) with $r_{1}=0.318$ and $r_{2}=0.013$ and copolymer composition $\mathrm{p}$ (triangles) determined by IR spectroscopy for $10 \mathrm{P}_{7-69}$

Increasing the $\mathrm{P}_{7}$ content in $B \mathrm{E}_{45} \mathrm{P}_{7}$ leads to a strong decrease in resistivity which passes a minimum at a mass fraction of 0.5 (Fig. 9A) after that the resistivity further increases. At the minimum, the resistivity is approximately $1 / 5$ of the value of pure $50 \mathrm{E}_{45}$ and approximately $1 / 3$ of that of pure $10 \mathrm{P}_{7}$. It should be noted that the resistance of $23 B \mathrm{E}_{45} \mathrm{P}_{7}$ falls below the lower limit predicted by the rule of mixtures already at $w>0.2$ (Supplementary Fig. S9). The degree of crystallinity also decreases with increasing amount of $10 \mathrm{P}_{7}$ and reaches 0 at $\mathrm{w}=0.5$, which means that from this point on, the materials are fully amorphous (Fig. 9B). As expected, the opposite behaviour is found for the $\left\langle T_{2}\right\rangle$ values except for the pure $50 \mathrm{E}_{45}$, which has higher $\left\langle T_{2}\right\rangle$ values due to its powdery texture. The $\left\langle T_{2}\right\rangle$ values increase up to $\mathrm{w}=0.5$ indicating the blends become more flexible as crystallisation is increasingly suppressed. Increasing the $\mathrm{P}_{7}$ content to more than $\mathrm{w}=0.5$ results in an increased stiffness due to the formation of a denser, less flexible network consisting of more shorter chains (Fig. 9C). This is clearly reflected in the $\left\langle T_{2}\right\rangle$ and $T_{\mathrm{g}}$ values and negatively affects the resistance of the resulting polyester network. The increasing influence of $\mathrm{P}_{7}$ on material properties can be observed by means of the glass transition temperatures, which remain almost constant at low $\mathrm{P}_{7}$ contents $\left(T_{\mathrm{g}}\right.$ approx. $-45^{\circ} \mathrm{C}$ at $\mathrm{w}<0.4)$, followed by a jump at approx. $\mathrm{w}=0.5$ and a subsequent exponential increase to $+5{ }^{\circ} \mathrm{C}$ at $\mathrm{w}=1$ (Fig. 9D).

\section{Conclusions}

In contrast to PEO-based unsaturated polyesters, the resistivity of cross-linked PPO systems decreases with increasing molecular weight, i.e. the conductivity increases for the PPO-based systems and decreases for the PEO-based ones. Despite the increased viscosity of the non-cross-linked precursors, networks formed by higher molecular weight PPO are more 

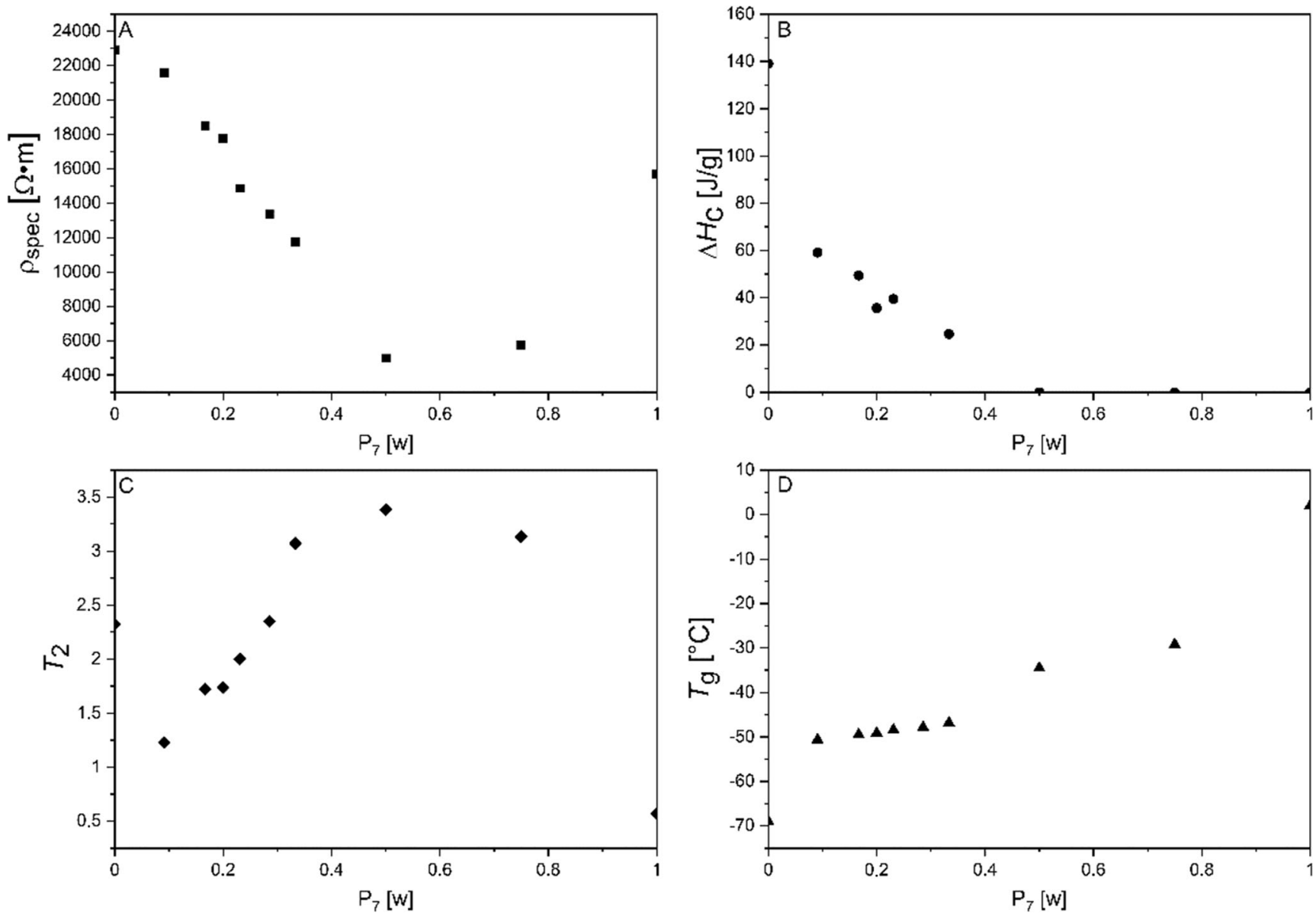

Fig. 9 Development of the (squares) resistance, (circles) degree of crystallinity, (diamonds) $\left\langle T_{2}\right\rangle$ values and (triangles) glass transition temperature for $50 \mathrm{E}_{45}$ and $10 \mathrm{P}_{7}$ blends cured with styrene in dependence of the $10 \mathrm{P}_{7}$ mass fraction $(\mathrm{w})\left(9-75 B \mathrm{E}_{45} \mathrm{P}_{7}\right)$

flexible than the lower molecular weight representatives. This is due to the larger mesh sizes and the fully amorphous nature of PPO. In addition, pronounced intrachain hopping along high molecular weight chains as opposed to time-consuming interchain hopping between the shorter chains of low molecular weight networks can be presumed. Single-sided nuclear magnetic resonance spectroscopy was found to be a valuable tool to quickly and accurately assess the chain mobility within a given set of samples of comparable consistency. This correlates with the resistivity (and inversely with the conductivity) of the samples. Due to the different effects on the conductivity of the cross-linked samples by the monomer types and chain lengths, it is possible to optimise the ionic conductivity by targeted blending and cross-linking of lithium-doped PEOand PPO-based unsaturated polyesters. The minimum resistivity of these networks is significantly below the lower limit predicted by the rule of mixtures. This indicates the importance of cross-linking, which sparks synergistic effects in the network. Apart from synergistic conductivity effects shown by the described cross-linked PEO-PPO network, a further advantage of these systems is the rubber elasticity and high tolerance of water as previously described. [40] These properties allow for widespread applications under mechanical stresses, under atmospheric conditions, or even in aqueous environments, which is problematic for standard ionconducting systems. [76-80]

Supplementary Information The online version contains supplementary material available at https://doi.org/10.1007/s11581-021-04149-z.

Code availability "Not applicable" for that section.

Author contribution All authors were involved in the conceptualisation. PS carried out the lab experiments, PS wrote the original draft and OW reviewed and edited the manuscript.

Funding Open Access funding enabled and organized by Projekt DEAL. The work was funded by the Federal Ministry of Economic Affairs and Energy through the ZIM programme (Zentrales Innovationsprogram Mittelstand) under Grant No. ZF2669716KM4. 
Data availability The data that support the findings of this study are available from the corresponding author upon reasonable request.

\section{Declarations}

Ethics approval "Not applicable" for that section.

Consent to participate All authors have given their consent to participation.

Consent for publication All authors have given their consent to publication.

Conflict of interest The authors declare no competing interests.

Open Access This article is licensed under a Creative Commons Attribution 4.0 International License, which permits use, sharing, adaptation, distribution and reproduction in any medium or format, as long as you give appropriate credit to the original author(s) and the source, provide a link to the Creative Commons licence, and indicate if changes were made. The images or other third party material in this article are included in the article's Creative Commons licence, unless indicated otherwise in a credit line to the material. If material is not included in the article's Creative Commons licence and your intended use is not permitted by statutory regulation or exceeds the permitted use, you will need to obtain permission directly from the copyright holder. To view a copy of this licence, visit http://creativecommons.org/licenses/by/4.0/.

\section{References}

1. Xue Z, He D, Xie X (2015) Poly(ethylene oxide)-based electrolytes for lithium-ion batteries. J Mater Chem A 3(38):19218-19253

2. Somani PR, Radhakrishnan S (2003) Electrochromic materials and devices: present and future. Mater Chem Phys 77(1):117-133

3. Juraschek T, Weichold O (2017) Development of an electrochromic device triggered by the macrocell current in chloride-induced corrosion of steel-reinforced concrete. J Phys Org Chem 30(9):e3739

4. Xu K (2004) Nonaqueous liquid electrolytes for lithium-based rechargeable batteries. Chem Rev 104(10):4303-4418

5. Meyer WH (1998) Polymer electrolytes for lithium-ion batteries. Adv Mater 10(6):439-448

6. Choo Y, Halat DM, Villaluenga I, Timachova K, Balsara NP (2020) Diffusion and migration in polymer electrolytes. Prog Polym Sci 103:101220

7. Fenton DE, Parker JM, Wright PV (1973) Complexes of alkali metal ions with poly(ethylene oxide). Polymer 14(11):589

8. Shriver DF, Papke BL, Ratner MA, Dupon R, Wong T, Brodwin M (1981) Structure and ion transport in polymer-salt complexes. Solid State Ion 5:83-88

9. Borodin O, Smith GD (1998) Molecular dynamics simulations of poly(ethylene oxide)/LiI melts. 1. Structural and conformational properties. Macromolecules 31(23):8396-8406

10. Killis A, Le Nest JF, Gandini A, Cheradame H, Cohen-Addad JP (1984) Correlation among transport properties in ionically conducting cross-linked networks. Solid State Ion 14(3):231-237

11. Shi J, Vincent CA (1993) The effect of molecular weight on cation mobility in polymer electrolytes. Solid State Ion 60(1):11-17

12. Zhao Q, Stalin S, Zhao C-Z, Archer LA (2020) Designing solidstate electrolytes for safe, energy-dense batteries. Nat Rev Mater 5(3):229-252
13. Schauser NS, Nikolaev A, Richardson PM, Xie S, Johnson K, Susca EM, Wang H, Seshadri R, Clément RJ, Read de Alaniz J, Segalman RA (2021) Glass transition temperature and ion binding determine conductivity and lithium-ion transport in polymer electrolytes. ACS Macro Lett 10(1):104-109

14. Horowitz Y, Schmidt C, Yoon D-h, Riegger LM, Katzenmeier L, Bosch GM, Noked M, Ein-Eli Y, Janek J, Zeier WG, Diesendruck CE, Golodnitsky D (2020) Between liquid and all solid: a prospect on electrolyte future in lithium-ion batteries for electric vehicles. Energy Technol 8(11):2000580

15. Ratner MA, Shriver DF (1988) Ion transport in solvent-free polymers. Chem Rev 88(1):109-124

16. Druger SD, Nitzan A, Ratner MA (1983) Dynamic bond percolation theory: a microscopic model for diffusion in dynamically disordered systems. I. Definition and one-dimensional case. J Chem Phys 79(6):3133-3142

17. Unge M, Gudla H, Zhang C, Brandell D (2020) Electronic conductivity of polymer electrolytes: electronic charge transport properties of LiTFSI-doped PEO. Phys Chem Chem Phys 22(15):7680-7684

18. Berthier C, Gorecki W, Minier M, Armand MB, Chabagno JM, Rigaud P (1983) Microscopic investigation of ionic conductivity in alkali metal salts-poly(ethylene oxide) adducts. Solid State Ionics 11(1):91-95

19. Teran AA, Tang MH, Mullin SA, Balsara NP (2011) Effect of molecular weight on conductivity of polymer electrolytes. Solid State Ionics 203(1):18-21

20. Zhou D, Shanmukaraj D, Tkacheva A, Armand M, Wang G (2019) Polymer electrolytes for lithium-based batteries: advances and prospects. Chem 5(9):2326-2352

21. Armand M (1990) Polymers with ionic conductivity. Adv Mater 2(6-7):278-286

22. Scrosati B (1989) Ion-conducting polymer electrolytes. Philos Mag B 59(1):151-160

23. Wright PV (1975) Electrical conductivity in ionic complexes of poly(ethylene oxide). British Polymer Journal 7(5):319-327

24. Wintersgill MC, Fontanella JJ, Stallworth PE, Newman SA, Chung SH, Greenbaum SG (2000) Electrical conductivity, DSC and NMR studies of PEG and PPG containing lithium salts. Solid State Ionics 135(1):155-161

25. Mindemark J, Lacey MJ, Bowden T, Brandell D (2018) Beyond PEO - Alternative host materials for Li+-conducting solid polymer electrolytes. Prog Polym Sci 81:114-143

26. Matsumoto M, Uno T, Kubo M, Itoh T (2013) Polymer electrolytes based on polycarbonates and their electrochemical and thermal properties. Ionics 19(4):615-622

27. Mauger A, Julien CM, Paolella A, Armand M, Zaghib K (2019) Building better batteries in the solid state: a review. Materials 12(23):3892

28. Pesko DM, Jung Y, Hasan AL, Webb MA, Coates GW, Miller TF, Balsara NP (2016) Effect of monomer structure on ionic conductivity in a systematic set of polyester electrolytes. Solid State Ionics 289:118-124

29. Hall PG, G R D., JE McIntyre, IM Ward, DJ Banister,; Brocq KMFL (1986) Polymer Communications , 27, 98.

30. He Y, Liu N, Kohl PA (2021) Difunctional block copolymer with ion solvating and crosslinking sites as solid polymer electrolyte for lithium batteries. J Power Sources 481:228832

31. Watanabe M, Itoh M, Sanui K, Ogata N (1987) Carrier transport and generation processes in polymer electrolytes based on poly(ethylene oxide) networks. Macromolecules 20(3):569-573

32. Watanabe M, Nagano S, Sanui K, Ogata N (1986) Ion conduction mechanism in network polymers from poly(ethylene oxide) and poly(propylene oxide) containing lithium perchlorate. Solid State Ionics 18-19:338-342

33. Angell CA (1983) Fast ion motion in glassy and amorphous materials. Solid State Ionics 9-10(Part 1):3-16 
34. Khan MS, Shakoor A, Nisar J (2010) Conductance study of poly(ethylene oxide)- and poly(propylene oxide)-based polyelectrolytes. Ionics 16(6):539-542

35. Wang X-L, Fan L-Z, Mei A, Ma F-Y, Lin Y-H, Nan C-W (2008) Ionic transport behavior in poly(ethylene oxide)-poly(propylene oxide)-poly(ethylene oxide) and $\mathrm{LiClO} 4$ complex. Electrochim Acta 53(5):2448-2452

36. Zhang Y, Lu W, Cong L, Liu J, Sun L, Mauger A, Julien CM, Xie H, Liu J (2019) Cross-linking network based on Poly(ethylene oxide): solid polymer electrolyte for room temperature lithium battery. J Power Sources 420:63-72

37. Nest J-FL, Gandini A, Cheradame H (1988) Crosslinked polyethers as media for ionic conduction. British Polymer Journal 20(3):253268

38. Manuel Stephan A, Nahm KS (2006) Review on composite polymer electrolytes for lithium batteries. Polymer 47(16):5952-5964

39. Hu CP, Wright PV (1989) Ionic conductivity of unsaturated polyester resin networks containing LiCIO4. British Polymer Journal 21(5):421-427

40. Sassmann PB, Weichold O (2019) Preparation and characterisation of ion-conductive unsaturated polyester resins for the on-site production of resistivity sensors. Ionics 25(8):3971-3978

41. Meabe L, Huynh TV, Mantione D, Porcarelli L, Li C, O'Dell LA, Sardon H, Armand M, Forsyth M, Mecerreyes D (2019) UV-crosslinked poly(ethylene oxide carbonate) as free standing solid polymer electrolyte for lithium batteries. Electrochim Acta 302:414421

42. Mindemark J, Törmä E, Sun B, Brandell D (2015) Copolymers of trimethylene carbonate and $\varepsilon$-caprolactone as electrolytes for lithium-ion batteries. Polymer 63:91-98

43. Zhang B, Liu Y, Pan X, Liu J, Doyle-Davis K, Sun L, Liu J, Jiao X, Jie J, Xie H, Sun X (2020) Dendrite-free lithium metal solid battery with a novel polyester based triblock copolymer solid-state electrolyte. Nano Energy 72:104690

44. Polo Fonseca C, Neves S (2006) Electrochemical properties of a biodegradable polymer electrolyte applied to a rechargeable lithium battery. J Power Sources 159(1):712-716

45. Zuo C, Chen G, Zhang Y, Gan H, Li S, Yu L, Zhou X, Xie X, Xue Z (2020) Poly(E-caprolactone)-block-poly(ethylene glycol)-blockpoly( $\varepsilon$-caprolactone)-based hybrid polymer electrolyte for lithium metal batteries. J Membr Sci 607:118132

46. Rosenwinkel MP, Andersson R, Mindemark J, Schönhoff M (2020) Coordination effects in polymer electrolytes: fast $\mathrm{Li}+$ transport by weak ion binding. J Phys Chem C 124(43):23588-23596

47. Ye W, Zaheer M, Li L, Wang J, Xu H, Wang C, Deng Y (2020) Hyperbranched PCL/PS copolymer-based solid polymer electrolytes enable long cycle life of lithium metal batteries. J Electrochem Soc 167(11):110532

48. Sångeland C, Younesi R, Mindemark J, Brandell D (2019) Towards room temperature operation of all-solid-state Na-ion batteries through polyester-polycarbonate-based polymer electrolytes. Energy Storage Materials 19:31-38

49. Meabe L, Peña SR, Martinez-Ibañez M, Zhang Y, Lobato E, Manzano H, Armand M, Carrasco J, Zhang H (2020) Insight into the ionic transport of solid polymer electrolytes in polyether and polyester blends. J Phys Chem C 124(33):17981-17991

50. Lee TK, Andersson R, Dzulkurnain NA, Hernández G, Mindemark J, Brandell D (2021) Polyester-ZrO2 nanocomposite electrolytes with high Li transference numbers for ambient temperature allsolid-state lithium batteries. Batteries \& Supercaps 4(4):653-662

51. Eriksson T, Mindemark J, Yue M, Brandell D (2019) Effects of nanoparticle addition to poly( $\varepsilon$-caprolactone) electrolytes: crystallinity, conductivity and ambient temperature battery cycling. Electrochim Acta 300:489-496

52. Li Y, Liu M, Duan S, Liu Z, Hou S, Tian X, Cao G, Jin H (2021) A high-voltage hybrid solid electrolyte based on polycaprolactone for high-performance all-solid-state flexible lithium batteries. ACS Applied Energy Materials 4(3):2318-2326

53. Lv F, Wang Z, Shi L, Zhu J, Edström K, Mindemark J, Yuan S (2019) Challenges and development of composite solid-state electrolytes for high-performance lithium ion batteries. J Power Sources 441:227175

54. Zheng Y, Yao Y, Ou J, Li M, Luo D, Dou H, Li Z, Amine K, Yu A, Chen Z (2020) A review of composite solid-state electrolytes for lithium batteries: fundamentals, key materials and advanced structures. Chem Soc Rev 49(23):8790-8839

55. Johansson IL, Brandell D, Mindemark J (2020) Mechanically stable UV-crosslinked polyester-polycarbonate solid polymer electrolyte for high-temperature batteries. Batteries \& Supercaps 3(6):527-533

56. Zheng H, Zheng S, Guo Q (1997) Thermosetting polymer blends of unsaturated polyester resin and poly(ethylene oxide). I. Miscibility and thermal properties. J Polym Sci A Polym Chem 35(15):31613168

57. Boyard N, Sinturel C, Vayer M, Erre R (2006) Morphology and cure kinetics of unsaturated polyester resin/block copolymer blends. J Appl Polym Sci 102(1):149-165

58. Sinturel C, Vayer M, Erre R, Amenitsch H (2007) Nanostructured polymers obtained from polyethylene-block-poly(ethylene oxide) block copolymer in unsaturated polyester. Macromolecules 40(7): 2532-2538

59. Li X, Fu W, Wang Y, Chen T, Liu X, Lin H, Sun P, Jin Q, Ding D (2008) Solid-state NMR characterization of unsaturated polyester thermoset blends containing PEO-PPO-PEO block copolymers. Polymer 49(12):2886-2897

60. Builes DH, Tercjak A (2015) Effect of carboxylated poly(ethylene oxide-b-propylene oxide-b-ethylene oxide) block copolymer on nanostructured unsaturated polyester resin. RSC Adv 5(116): 96170-96180

61. Pandit SB, Nadkarni VM (1994) Toughening of unsaturated polyesters by reactive liquid polymers. 2 . Processibility and mechanical properties. Ind Eng Chem Res 33(11):2778-2788

62. Fang B, Hu CP, Ying SK (1993) Structure and ionic conductivity of graft polyester networks containing lithium perchlorate. Eur Polym J 29(6):799-803

63. Jannasch P (2001) Ion conducting electrolytes based on aggregating comblike poly(propylene oxide). Polymer 42(21):8629-8635

64. Cowie JMG, Cree SH (1989) Electrolytes dissolved in polymers. Annu Rev Phys Chem 40(1):85-113

65. Maitra A, Heuer A (2007) Cation transport in polymer electrolytes: a microscopic approach. Phys Rev Lett 98(22):227802

66. Halmen N, Kugler C, Kraus E, Baudrit B, Hochrein T, Bastian M (2018) Single-sided NMR for the measurement of the degree of cross-linking and curing. J Sens Sens Syst 7(1):21-30

67. Blümich B, Blümler P (1993) NMR imaging of polymer materials. Die Makromolekulare Chemie 194(8):2133-2161

68. Blümich B, Hagemeyer A, Schaefer D, Schmidt-Rohr K, Spiess HW (1990) Solid State NMR spectroscopy in polymer science. Adv Mater 2(2):72-81

69. Trivedi, B. (2013) Maleic Anhydride. Springer US.

70. Trivedi, B. C.; Culbertson, B. M. (1982) Maleic anhydride in condensation polymers. In Maleic Anhydride, Springer US: Boston, MA, pp 479-517.

71. Hsu CP, Lee LJ (1993) Free-radical crosslinking copolymerization of styrene/unsaturated polyester resins: 1 . Phase separation and microgel formation. Polymer 34(21):4496-4505

72. Hsu CP, Lee LJ (1993) Free-radical crosslinking copolymerization of styrene/unsaturated polyester resins: 3 . Kinetics-gelation mechanism Polymer 34(21):4516-4523

73. M.W. Urban, RSGT (1991) Provder, Polym. Comm. 32, 171.

74. Delahaye N, Marais S, Saiter JM, Metayer M (1998) Characterization of unsaturated polyester resin cured with styrene. J Appl Polym Sci 67(4):695-703 
75. Brandrup, J.; Immergut, E. H.; Grulke, E. A. (1999) Polymer handbook. Wiley.

76. Yang J, Liu Y, Liu S, Li L, Zhang C, Liu T (2017) Conducting polymer composites: material synthesis and applications in electrochemical capacitive energy storage. Materials Chemistry Frontiers 1(2):251-268

77. Lee BL (1992) Electrically conductive polymer composites and blends. Polym Eng Sci 32(1):36-42

78. Shirakawa H, Louis EJ, MacDiarmid AG, Chiang CK, Heeger AJ (1977) Synthesis of electrically conducting organic polymers: halogen derivatives of polyacetylene, $(\mathrm{CH})$. J Chem Soc Chem Commun 16:578-580
79. Livi F, Carlé JE, Bundgaard E (2015) Thiophene in conducting polymers: synthesis of poly(thiophene)s and other conjugated polymers containing thiophenes, for application in polymer solar cells. In: Joule JA (ed) Thiophenes. Springer International Publishing, Cham, pp 203-226

80. Orchard BJ, Freidenreich B, Tripathy SK (1986) Structural study of two conducting polymers: poly(pyrrole) and poly(thiophene). Polymer 27(10):1533-1541

Publisher's note Springer Nature remains neutral with regard to jurisdictional claims in published maps and institutional affiliations. 